\title{
Measuring System Performance \& User Satisfaction after Implementation of ERP
}

\author{
Imran Batada \\ Institute of Business Administration, \\ Karachi, Pakistan
}

imran.batada@khi.iba.edu.pk

\author{
Asmita Rahman \\ University of Georgia, \\ Athens, GA, USA
}

asmitab@uga.edu

\begin{abstract}
Now a day ERP systems are being adopted by various organizations as part of their business growth strategies. However, one must realize that implementation of an ERP system is not a goal but a journey towards the goal. Even after successful implementation, the goal is not achieved until the system is completely used. The satisfaction of the users and the overall performance must be measured periodically to evaluate the success of the implementation and the overall object of having the Enterprise level of System.

Our research paper uses and adapts the balanced scorecard method for the measurement of ERP performance. The model uses four interrelated dimensions i.e. (Financial, Customer, Internal Business \& Learning and Growth). The questionnaire criteria were developed based on the four dimensions of the model. We then carried out an extensive survey on one of the major institutions in Pakistan to evaluate their recent ERP implementation. All major stakeholders participated in the survey.

The results from the survey clearly indicated user satisfaction in one of the perspectives, while suggested dissatisfaction in another. Due to this research, we were clearly able to identify the problem area and offer recommendations to the organization for better performance of the ERP. This approach allows us to clearly identify the key performance indicators as well as their role in the total success of the ERP System.
\end{abstract}

Keywords: ERP System Performance, ERP User Satisfaction, ERP Audit, Balance Scorecard, ERP performance evaluation.

\section{Introduction}

Enterprise Resource Planning (ERP) System is the integrated system. It connects all departments within the organization. ERP System enables all the departments of an organization to share the central database. ERP system has a centralized structure consisting of central database which can

Material published as part of this publication, either on-line or in print, is copyrighted by the Informing Science Institute. Permission to make digital or paper copy of part or all of these works for personal or classroom use is granted without fee provided that the copies are not made or distributed for profit or commercial advantage AND that copies 1) bear this notice in full and 2) give the full citation on the first page. It is permissible to abstract these works so long as credit is given. To copy in all other cases or to republish or to post on a server or to redistribute to lists requires specific permission and payment of a fee. Contact Publisher@InformingScience.org to request redistribution permission. be retrieved by all the department(s).

(Batada \& Rahman, 2011)

This is one of the major benefits and therefore, many organizations implement this system. The ERP Selection, Implementation process not only requires money but also requires time and efforts of the functional stakeholders. In this paper, we will discuss the journey after the implementation of ERP in the 
Organization. We will also discuss how to evaluate the overall ERP Performance from the user perspective.

\section{Related Works:}

Enterprise System helps organization to improve the overall communication and it helps the organization to achieve their strategic goals. ERP implementation is not only the implementation or installation of robust software; it is the achieved by the efforts of all the stakeholders of the organization.

Successful implementation of ERP is not the selection of right product or selection of right vendors it is towards the utilization factor of the System. How much organization is dependent on the System is one of the key factors used to analyze the performance of the system.

\section{Relevant Methods for ERP Performance Measurement:}

There are several methods available for evaluating the performance of the ERP System. Most of the methods are based on metrics calculation evaluating the financial return of investment. However, in terms of the evaluation of an ERP system there are three Performance measurements that have been identified by Chun Chin (Wei, Liou, \& Lee-2008); they are construction of performance indicator, group ERP performance measurement, and analysis of result and system improvement. (Wei, Liou, \& Lee. 2007)

ERP Systems are enterprise level System so it is complex to measure the performance. The Analytical Approach based on the flow network model is used by (Chen, Lin. 2008) for measuring the performance of ERP. Stochastic Flow network model is proposed to be used and then they proposed their algorithm for evaluating performance.

In another research (Ho 2006) integrated approach was considered for evaluation the performance of ERP. They observed the cost structure ratio and lead time uncertainty within the own operating environment.

The Balanced Scorecard Method highlights the four major perspectives of the organization (financial/cost, customer, internal processes, and innovation and learning) since it is covering all the areas and perspectives it is an efficient way of measurement. Project Perspectives were added in the balanced scorecard approach by (Rosemann \& Wiese 1999).

\section{Selection of Balanced Scorecard for ERP Performance System:}

The Balanced Scorecard method for ERP Performance System was successfully carried out in a higher education institute in Karachi, Pakistan. The university had recently implemented the ERP System and they wanted to evaluate the overall performance of the System and assess the overall advantage of the implementation of the System.

\section{Survey design:}

The university's ICT Department prepared a questionnaire comprising 48 questions for evaluating the overall performance of the System. The questionnaire was distributed in the form of an online survey system. All the major stake holders of the university participated in the survey and results were recorded anonymously. The questionnaire was divided into four major categories i.e. Learning and Growth, Internal Business, Customer and Financial.

\section{Research method- Balanced scorecard:}

A balanced scorecard can be defined as a planning and management system that is commonly used by organizations, companies etc. for monitoring or assessing the performance against the 
global goals. The balanced scorecard has evolved from its early use as a simple performance measurement framework to a full strategic planning and management system.

According to the balance scorecard approach we look at the organization from four perspectives. The four perspectives that were considered were Financial, Customer, Internal Business \& Learning and Growth. Data was collected and analyzed relative to each of the perspective. Here is a diagram that illustrates the balanced scorecard method:

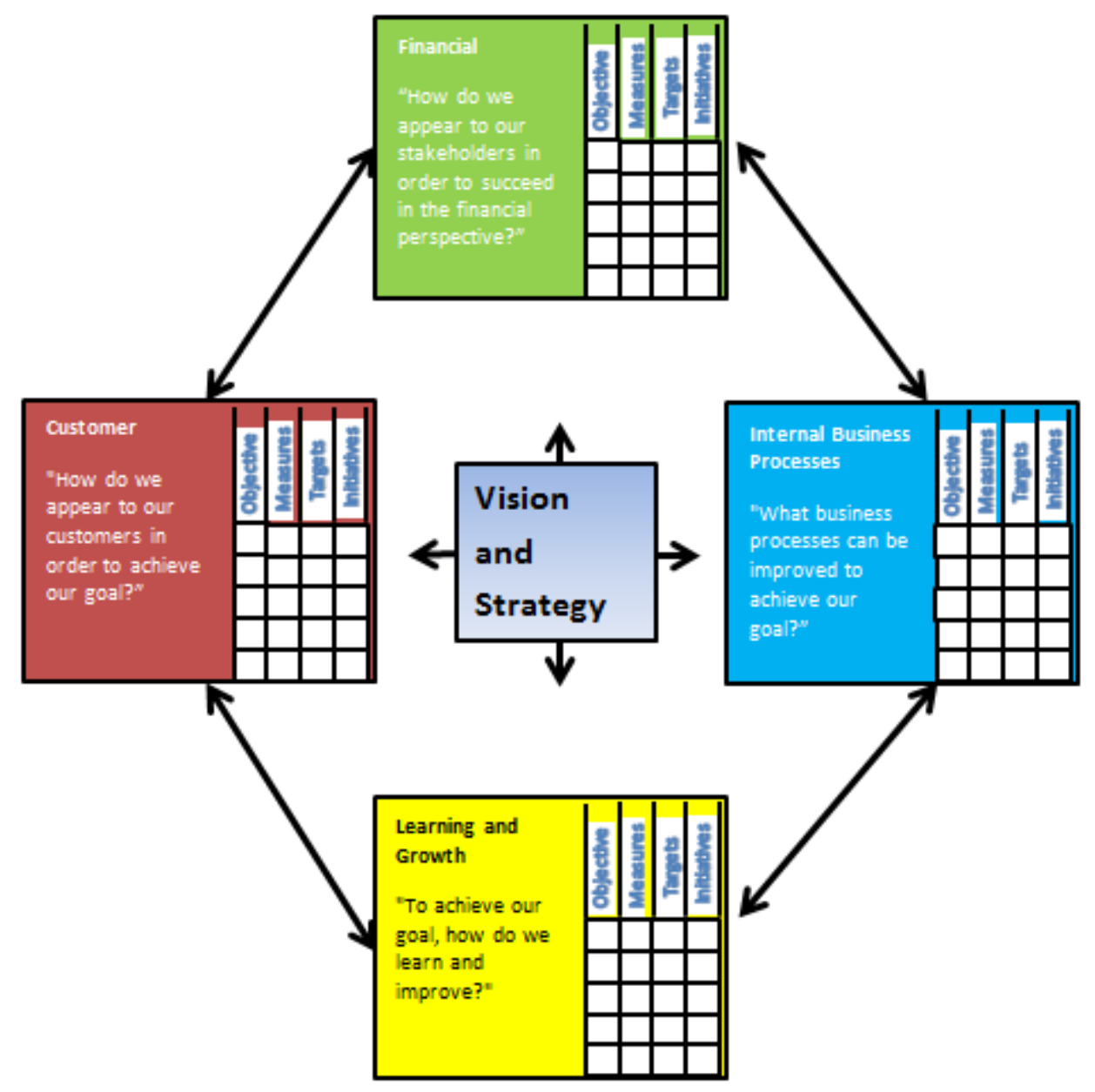

Figure 1: Balance Scorecard approach for performance measurement Source: Kaplan \& Norton, 1996

\section{Balanced Scorecard Implementation:}

Data for our research was collected in form of a survey. The survey consisting of 48 questions was divided among the four perspectives. All the stake holders participated in the survey. Here is the division of questions based on the perspectives:

Learning and growth Perspective: 12

Internal Business and Growth Perspective: 16

Customer Perspective: 12

Financial Perspective: 8 


\section{Performance Evaluation:}

\section{Perspective \# 1: Learning and growth}

This perspective was further divided into three matrices, enabling better classification of the questions. These three matrices consist of the following questions:

\section{Matrix 1:}

Question No 1: Is the ERP Data accurate? Learning and Growth

Question No 2: Are you comfortable to rely on the system information?

Question No 3: Are you or your department capable to take care of your reporting requirements?

Question No 4: Did the ERP System increase your productivity?

Average Weightage of the questions: 5

Average response score for this matrix: 3.88

Score of Matrix 1: Weightage of questions $*$ Score of questions $=0.775$

\section{Matrix 2:}

Question No 5: Are you getting up-to-date information from the System?

Question No 6: Are you getting required information instantly from the System?

Question No 7: The information which was only available via other departments earlier, is now available via the system.

Question No 8: Strong Information Systems (IS) Department

Average Weightage of the questions: 5

Average response score for this matrix: 3.716

Score of Matrix 2: Weightage of questions $*$ Score of questions $=0.7433$

\section{Matrix 3:}

Question No 9: Technical knowhow of the ERP team

Question No 10: Strong and meaningful training programs

Question No 11: Do you now have a decent understanding of ERP concepts

Question No 12: Did you already have a reliable IT infrastructure in place

Average Weightage of the questions: 5

Average response score for this matrix: 3.83

Score of Matrix 3: Weightage of questions $*$ Score of questions $=0.7666$

The Performance of the perspective is now calculated by the following formula:

Performance of Learning and Growth Perspective:

$$
\sum_{i=1}^{n} \square^{n} \text { Wotghtage of Matrtx(i) * Score of Matrtx (i) }
$$

Since there were three matrices in this perspective, they all have a weightage of .03333 . Here is the performance of our first perspective:

Performance $($ Learning and growth Perspective $)=(0.333 * 0.775)+(0.333 * 0.7433)+$ $(0.333 * 0.7666)$

Performance (Learning and growth Perspective $)=0.761667$ 


\section{Perspective \# 2: Internal business perspective:}

This perspective was further divided into four matrices, enabling better classification of the questions. These four matrices consist of the following questions:

\section{Matrix 1:}

Question No 1: Is the System efficient to take your needs?

Question No 2: Is the ERP System advantageous?

Question No 3: Does the ERP system aid your decision making process?

Question No 4: Are you getting good ERP Technical Support?

Average Weightage of the questions: 5

Average response score for this matrix: 3.98

Score of Matrix 1: Weightage of questions $*$ Score of questions $=0.795$

\section{Matrix 2:}

Question No 5: Are you or your department being trained on time?

Question No 6: Does the ERP System ease your work load?

Question No 7: Does the ERP system provide you accurate information for your daily routine tasks?

Question No 8: Does the ERP System provide you the information for easy decision making?

Average Weightage of the questions: 5

Average response score for this matrix: 3.87

Score of Matrix 2: Weightage of questions $*$ Score of questions $=0.7733$

\section{Matrix 3:}

Question No 9: Did this implementation result in reduced paper work

Question No 10: Did the feeling of ownership of the system improve after the implementation among the functional users as well as end users

Question No 11: The interdepartmental relationships improved

Question No 12: Overall group / departmental productivity improved

Average Weightage of the questions: 5

Average response score for this matrix: 3.71

Score of Matrix 3: Weightage of questions $*$ Score of questions $=0.741$

\section{Matrix 4:}

Question No 13: Better coordination in between different departments

Question No 14: Streamlined the business processes

Question No 15: Increased overall satisfaction with business processes

Question No 16: Improve the organizational processes as a whole

Average Weightage of the questions: 5

Average response score for this matrix: 3.733

Score of Matrix 4: Weightage of questions $*$ Score of questions $=0.746$ 
Performance of Internal Business Perspective:

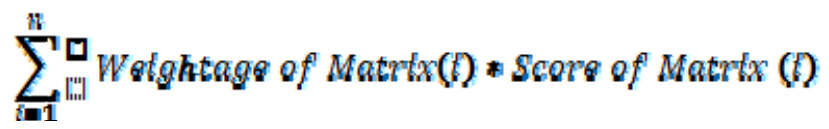

Since there were four matrices in this perspective, they all have a weightage of .25 . Here is the performance of our second perspective:

Performance $($ Internal Business Perspective $)=(0.25 * 0.795)+(0.25 * 0.773)+$ $(0.25 * 0.741)+(0.25 * 0.746)$

Performance $($ Internal Business Perspective $)=0.76416$

\section{Perspective \# 3: Customer perspective:}

This perspective was further divided into three matrices, enabling better classification of the questions. These three matrices consist of the following questions:

\section{Matrix 1:}

Question No 1: Did you get any benefit out of resource utilization? Customer

Question No 2: Are you getting timely reports from the System?

Question No 3: User's involvement and participation

Question No 4: For how long do you use the system daily?

Average Weightage of the questions: 5

Average response score for this matrix: 3.875

Score of Matrix 1: Weightage of questions $*$ Score of questions $=0.775$

\section{Matrix 2:}

Question No 5: Are you or your team capable to handle the ERP Functional

Side?

Question No 6: Is the ERP System user friendly?

Question No 7: What is your opinion about the overall performance of the Sys-

tem?

Question No 8: ERP simplifies user task

Average Weightage of the questions: 5

Average response score for this matrix: 3.558

Score of Matrix 2: Weightage of questions $*$ Score of questions $=0.7116$

\section{Matrix 3:}

Question No 9: Top management support

Question No 10: Functional areas support

Question No 11: ERP support within the organization

Question No 12: Your opinion about ERP software selected

Average Weightage of the questions: 5

Average response score for this matrix: 3.866

Score of Matrix 3: Weightage of questions $*$ Score of questions $=0.7733$ 
Performance of Customer Perspective:

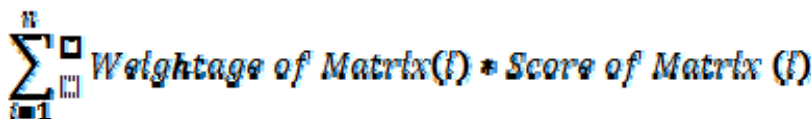

Since there were three matrices in this perspective, they all have a weightage of 0.33 . Here is the performance of our third perspective:

$$
\text { Performance }(\text { Customer Perspective })=(0.33 * 0.775)+(0.33 * 0.7116)+(0.33 * 0.773)
$$

Performance $($ Customer Perspective $)=0.75333$

\section{Perspective \# 4: Financial perspective:}

This perspective was further divided into two matrices, enabling better classification of the questions. These two matrices consist of the following questions:

\section{Matrix 1:}

Question No 1 ERP helps in saving end user time

Question No 2: Was there a decrease in overall operating cost after implementing the System?

Question No 3: Was there any staff reduction?

Question No 4: Efficient change management

Average Weightage of the questions: 5

Average response score for this matrix: 3.691

Score of Matrix 1: Weightage of questions $*$ Score of questions $=0.7383$

\section{Matrix 2:}

Question No 5: Strategic planning for the ERP Project

Question No 6: Forecasting process has been improved

Question No 7: Are you dependent on the ERP System for your daily operational activities?

Question No 8: Has the system improved your performance?

Average Weightage of the questions: 5

Average response score for this matrix: 3.7333

Score of Matrix 2: Weightage of questions $*$ Score of questions $=0.7466$

Performance of Financial Perspective:

$$
\sum_{i=1}^{n} \square \text { Wotghtage of Matrtx(t) * Scor of Matrtx (b) }
$$

Since there were three matrices in this perspective, they all have a weightage of 0.5 . Here is the performance of our fourth perspective:

$$
\begin{aligned}
& \text { Performance }(\text { Financial Perspective })=(0.50 * 0.7383)+(0.50 * 0.7466) \\
& \text { Performance }(\text { Financial Perspective })=0.7425
\end{aligned}
$$




\section{Calculation of overall performance:

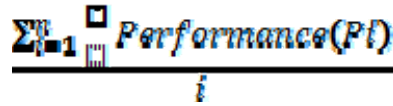

Overall Performance: $(0.761667+0.76416+0.75333+0.7425) / 4$

Overall Performance: 0.755416667

\section{Evaluation Criteria:}

The following scale was used to measure the performance of our system:

\begin{tabular}{|l|l|l|}
\hline Scale: & & \\
\hline & Excellent & 0.81 to 0.10 \\
\hline & Good & 0.61 to 0.8 \\
\hline & Fair & 0.51 to 0.6 \\
\hline & Poor & 0.0 to 0.5 \\
\hline
\end{tabular}

\section{Critical Analysis}

Our overall performance score as calculated above is 0.755416667 , which falls under the ranking of "Good" in the standard scale. We can see the performance of each perspective to evaluate the areas that need more improvement. Our performance was equal in all the perspectives, however, as we can see the financial perspective scored the least. Based on this evaluation, we can conclude that this perspective needs improvement. We can improve is by decreasing the over-all cost of the implementation as well as by providing more value to its users in terms of decreasing the daily operational costs.

Learning \& Development showed 0.76 which indicates that there is a good room for improvement. It has the areas of accuracy of data, productivity of users, reliance on the system of the user and reporting requirements. 0.76 falls in the "good" category but it still a little far from excellent.

Internal Business Perspective showed 0.79; which also indicates the room for improvement in this area. It includes the areas of training; ease your work load, daily routine operations and the decision making. This can be improved by arranging more training sessions so that users will get trained or they get a refresher of the system. This will definitely improve the reliance of the system ratio and finally they would be able to take decision via the System.

Customers Perspective showed 0.75 is also good rating but can be improved by providing functional area support, inter departmental meetings, rewards from the top management etc. ERP System is interconnected with other departments therefore; the interdepartmental support is required to increase the ranking of this phase.

Financial Perspective showed 0.74 indicating it has room for improvement as well. Improvement in this phase will definitely help organization in terms of overall growth.

\section{Conclusion}

Measurement of ERP System's performance is necessary for the organization both who recently implemented as well as for those who implemented it in last several years. It is necessary for all the stakeholders to participate in the evaluation process. This will enable the organization to make 
proper improvements. Balanced Scorecard helps the organization evaluate the system based on four major perspectives.

In this research we used Balance Scorecard for evaluating the performance of ERP System. Questionnaire was prepared and extensive online survey was conducted to evaluate four major perspectives. Over-all our evaluation rated the implementation as "good'. It also provided in depth analysis on various areas of improvements. With the help of the balance scorecard approach, the system was evaluated on four major criterions.

\section{References}

Batada, I., \& Rahman, A., (2011). Selection, implementation \& post production of an ERP System. Proceedings of the 2nd International Conference on Information Management and Evaluation.

Chen, S., \& Lin, Y. (2008). An evaluation method for enterprise resource planning systems. Journal of the Operations Research Society of Japan.

Dahne, S., Hohne, J., \& Tangermann M. (2011). Adaptive classification improves control performance in ERP-based BCIs. Proceedings of the 5th International BCI Conference 2011.

Ho, C. (2006). Measuring system performance of an ERP-based supply chain. International Journal of Production Research.

Hyvonen, J. (2007) Strategy, performance measurement techniques and information technology of the firm and their links to organizational performance. Management Accounting Research, 18.

Kaplan, R. S., \& Norton, D. P. (1996). Using the balanced scorecard as a strategic management system, Harvard Business Review.

Rosemann, M., \& Wiese, J. (1999). Measuring the performance of ERP software- A balanced scorecard approach. 10th Australasian Conference on Information Systems, 1999. .

Wei, C., Liou, T., \& Lee, K. (2008). An ERP performance measurement framework using a fuzzy integral approach. Journal of Manufacturing Technology Management.

\section{Biographies}

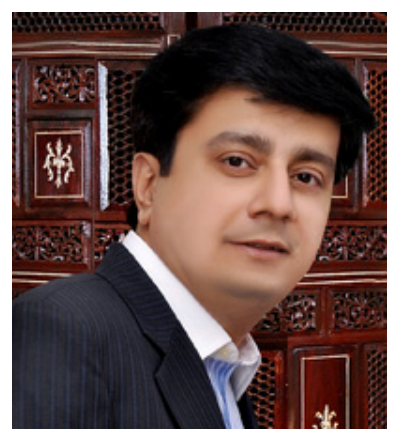

Imran Batada is a senior IT Professional with over 10 years of experience in the IT industry. As an IT Professional he has worked in USA and Asia.

He is currently working in Institute of Business Administration, Karachi Pakistan as Head of Information System Department. He is also responsible for overall ERP Implementation.

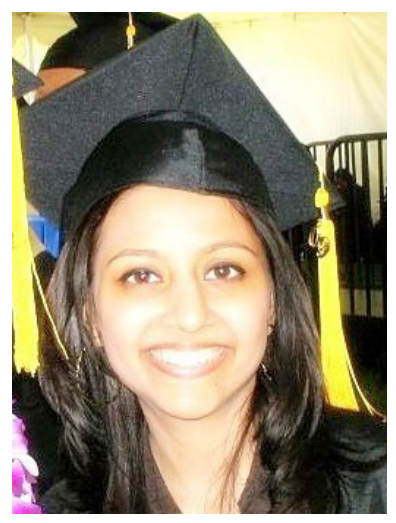

Asmita Rahman, raised in Los Angeles California, currently pursuing her Masters in Computer Science from the University of Georgia. She completed her Bachelors in Computer Science from California State University in 2009. Her Areas of research include ERP implementation, post implementation of ERP and Semantic Web. 